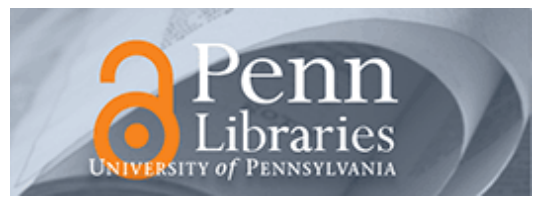

University of Pennsylvania ScholarlyCommons

$10-2014$

\title{
Commitment Devices to Improve Unhealthy Behaviors-Reply
}

Todd Rogers

Harvard University

Katherine L. Milkman

University of Pennsylvania

Kevin G. Volpp

University of Pennsylvania

Follow this and additional works at: https://repository.upenn.edu/hcmg_papers

Part of the Substance Abuse and Addiction Commons

\section{Recommended Citation}

Rogers, T., Milkman, K. L., \& Volpp, K. G. (2014). Commitment Devices to Improve Unhealthy Behaviors-Reply. JAMA (Journal of the American Medical Association), 312 (15), 1592-1593. http://dx.doi.org/10.1001/jama.2014.10173

This paper is posted at ScholarlyCommons. https://repository.upenn.edu/hcmg_papers/29

For more information, please contact repository@pobox.upenn.edu. 


\title{
Commitment Devices to Improve Unhealthy Behaviors-Reply
}

\author{
Abstract \\ In Reply Our Viewpoint described commitment devices and argued that they should be more widely used \\ in health care. Commitment devices enforce voluntarily imposed restrictions on people until they have \\ accomplished their goals or enforce voluntarily imposed penalties if they do not accomplish their goals. \\ Disciplines \\ Substance Abuse and Addiction
}


segment of the population is resistant to adopting new behaviors, as described in the diffusion of innovation theory. ${ }^{3}$

Although this portion of the population is not included in studies on commitment devices, a negative response to any intervention might be expected. Initial predisposition to change will affect the perception of the intervention and its effectiveness on behavior change.

Second, as commitment devices are implemented in the general population, it is important to carefully consider how these interventions are perceived based on research on framing and behavior change. A commitment device can be perceived positively as a motivator, reinforcing new behaviors (carrot). But the same commitment device can be perceived as a requirement, which unless fulfilled, will lead to the loss of a previously acquired privilege (stick).

Tversky and Kahneman ${ }^{4}$ showed that response to change is more intense when the changes are unfavorable (result in losses) than when they result in improvements. Yet the feeling of constraint can decrease a person's willingness to adopt a new behavior and can shift motivation from intrinsic to extrinsic. ${ }^{5}$ Because long-term change is more effective with intrinsic motivation, this form of nudging for the general population may actually have an unintended negative effect.

As public health policies seek to nudge the population to healthier behaviors, the implementation of commitment devices or other default changes should include careful consideration of patient perceptions.

\section{Katherine Blondon, MD, PhD}

Author Affiliation: Faculty of Medicine, University of Geneva, Geneva, Switzerland.

Corresponding Author: Katherine Blondon, MD, PhD, University of Geneva, Faculty of Medicine, Rue Gabrielle-Perret-Gentil 4, Geneva 1211, Switzerland (katherine.blondon@unige.ch).

Conflict of Interest Disclosures: The author has completed and submitted the ICMJE Form for Disclosure of Potential Conflicts of Interest and none were reported.

1. Rogers T, Milkman KL, Volpp KG. Commitment devices: using initiatives to change behavior. JAMA. 2014;311(20):2065-2066.

2. Thaler RH, Sunstein CR. Nudge: Improving Decisions About Health, Wealth, and Happiness. New York, NY: Penguin; 2009.

3. Rogers EM. Diffusion of Innovations. 4th ed. New York, NY: Free Press; 1995.

4. Tversky A, Kahneman $D$. The framing of decisions and the psychology of choice. Science. 1981;211(4481):453-458.

5. Ryan RM, Deci EL. Intrinsic and extrinsic motivations: classic definitions and new directions. Contemp Educ Psychol. 2000;25(1):54-67.

In Reply Our Viewpoint described commitment devices and argued that they should be more widely used in health care. Commitment devices enforce voluntarily imposed restrictions on people until they have accomplished their goals or enforce voluntarily imposed penalties if they do not accomplish their goals.

Taking disulfiram in the morning so a person with alcoholism will be sick if he or she drinks alcohol in the evening is an example of a commitment device. Scheduling workouts with a partner to increase the cost of skipping the gym (ie, disappointing friends) is another example of a commitment de- vice. Recent behavioral science research finds significant demand for commitment devices and that such devices can improve health outcomes ranging from weight loss to smoking cessation.

An obvious question is why would anyone voluntarily impose restrictions on himself or herself. The answer is that some people are self-aware about the fact that owing to limited willpower, they sometimes do not follow through on their best intentions and thus could fail to accomplish their current health goals. These people find commitment devices attractive as a means of precommitting themselves to pursuing healthy future behaviors.

Dr Blondon raises the possibility that encouraging increased use of commitment devices may have some unintended negative consequences. The hypotheses she puts forth can only be tested with data, and we agree that future research is needed. In fact, our Viewpoint called for additional research addressing such important open questions. That said, we respectfully contest Blondon's predictions about what such research would uncover.

Blondon's first proposition is that individuals who would not readily adopt commitment devices without encouragement may react unfavorably if they are urged to adopt them. We would predict just the opposite. Persons who most readily adopt commitment devices are unusually self-aware about the risk that they may not achieve their health goals due to future willpower failures. ${ }^{1}$ Such self-aware patients are the most likely to seek out and use other support systems and therefore may be likely to benefit the least from commitment devices.

The second concern Blondon raises is that experiencing the restrictions associated with commitment devices could suppress intrinsic motivation and therefore suppress future demand for commitment devices. A recent study found that the majority (57\%) of people who experienced an externally imposed restriction designed to induce more exercise subsequently elected to self-impose the same restriction (ie, use it as a commitment device) to motivate more exercise moving forward. ${ }^{2}$ Thus, the only evidence we know of to date addressing this issue suggests commitment devices do not appear to undermine future motivation.

Even though more research is needed on how best to encourage the use of commitment devices and who will benefit most from them, we believe that they can and should be used to improve societal health outcomes.

\section{Todd Rogers, $\mathrm{PhD}$}

Katherine L. Milkman, PhD

Kevin G. Volpp, MD, PhD

Author Affiliations: Harvard Kennedy School, Harvard University, Boston, Massachusetts (Rogers); Wharton School, University of Pennsylvania, Philadelphia (Milkman); Philadelphia VA Medical Center, UPENN Center for Health Incentives and Behavioral Economics, Philadelphia, Pennsylvania (Volpp).

Corresponding Author: Kevin G. Volpp, MD, PhD, Philadelphia VA Medical Center, Perelman School of Medicine and Wharton School, Center for Health Incentives and Behavioral Economics, University of Pennsylvania, 423 Guardian Dr, Philadelphia, PA 19104 (volpp70@exchange.upenn.edu). 
Conflict of Interest Disclosures: The authors have completed and submitted the ICMJE Form for Disclosure of Potential Conflicts of Interest. Dr Volpp reported receiving institutional grant funding from the National Institutes of Health; serving as a consultant to CVS Caremark and VALHealth (of which he is a part owner); and receiving grants from CVS Caremark, Humana, Merck, Weight Watchers, and Discovery (South Africa). No other disclosures were reported.

1. O'Donoghue T, Rabin M. Doing it now or later. Am Econ Rev. 1999;89(1): 103-124.

2. Milkman KL, Minson JA, Volpp KG. Holding the hunger games hostage at the gym: an evaluation of temptation bundling. Manage Sci. 2014;60(2):283-299.

\section{Editor's Note \\ Clarification of Inaccurate Statement}

The editors would like to clarify the last sentence of the first paragraph of the Brief Report entitled "Medical Communication Companies and Industry Grants" published in the December 18, 2013, issue of JAMA, as we believe the sentence could be read as suggesting that all medical communication companies participate in certain marketing activities, which is not accurate. The authors disagree with this interpretation and the need for a clarification. The sentence has been modified online to read: "Known best for arranging continuing medical education (CME) programs, they also may develop prelaunch and branding campaigns and produce digital and print publications.”

\section{CORRECTION}

Clarification: In the Brief Report entitled "Medical Communication Companies and Industry Grants" published in the December 18, 2013, issue of JAMA (2013;310[23]: 2554-2558. doi:10.1001/jama.2013.281638), the last sentence of the first paragraph in the article requires clarification. It should read: "Known best for arranging continuing medical education (CME) programs, they also may develop prelaunch and branding campaigns and produce digital and print publications." This article was corrected online.

Errors in Clinical Crossroads: In the Clinical Crossroads article entitled "Assessment and Lifestyle Management of Patients With Obesity: Clinical Recommenda- tions From Systematic Reviews," published in the September 3, 2014, issue of JAMA (2014;312[9]:943-952. doi:10.1001/jama.2014.10432), several errors occurred. On page 944 , in the third paragraph of the left column, the second sentence should have read "Her only medication is paroxetine, $50 \mathrm{mg} / \mathrm{d}$." On page 945 , the secondto-last sentence of the second paragraph under "Taking an Obesity-Focused History" also should have stated that Ms T is taking paroxetine, not fluoxetine. On page 950, in the paragraph under "Recommendations for Ms T," the third sentence should have stated that Ms T should try to accumulate at least 150 minutes of moderately vigorous physical activity on a weekly basis [not a daily basis] and discuss with her physician the substitution of paroxetine [not fluoxetine] with an alternative antidepressant. This article was corrected online.

\section{Guidelines for Letters}

Letters discussing a recent JAMA article should be submitted within 4 weeks of the article's publication in print. Letters received after 4 weeks will rarely be considered. Letters should not exceed 400 words of text and 5 references and may have no more than 3 authors. Letters reporting original research should not exceed 600 words of text and 6 references and may have no more than 7 authors. They may include up to 2 tables or figures but online supplementary material is not allowed. All letters should include a word count. Letters must not duplicate other material published or submitted for publication. Letters not meeting these specifications are generally not considered. Letters being considered for publication ordinarily will be sent to the authors of the JAMA article, who will be given the opportunity to reply. Letters will be published at the discretion of the editors and are subject to abridgement and editing. Further instructions can be found at http://jama.com/public /InstructionsForAuthors.aspx. A signed statement for authorship criteria and responsibility, financial disclosure, copyright transfer, and acknowledgment and the ICMJE Form for Disclosure of Potential Conflicts of Interest are required before publication. Letters should be submitted via the JAMA online submission and review system at http: //manuscripts.jama.com. For technical assistance, please contact jama-letters@jamanetwork.org.

Section Editor: Jody W. Zylke, MD, Deputy Editor. 